\title{
IMPLEMENTASI VISIBLE LIGHT COMMUNICATION (VLC) UNTUK PENGIRIMAN TEKS
}

(Implementation Of Visible Light Communication (VLC) for Sending Text)

Des Hariangga Trihantoro ${ }^{[1]}$, Denny Darlis, S.Si,. MT. ${ }^{[2]}$, Hasanah Putri, ST,. MT. ${ }^{[3]}$

Prodi D3 Fakultas Ilmu Terapan, Universitas Telkom

Jl. Telekomunikasi no.1 Dayeuhkolot Bandung 40257 Indonesia

dezhariangga@yahoo.co.id, dennydarlis@telkomuniversity.ac.id, hasanahputri@telkomuniversity.ac.id

\begin{abstract}
Intisari- Perkembangan teknologi menciptakan banyak inovasi, salah satunya adalah lampu rumah berbasis LED yang nantinya tidak hanya digunakan sebagai penerangan saja tetapi juga untuk media komunikasi. cahaya LED digunakan untuk pemanfaatan Visible Light Communication sebagai pengiriman berbasis teks.

Sistem komunikasi visible light communication dapat memungkinkan untuk mengirimkan data berbasis teks. Pada blok Transmiter terdiri atas pengirim informasi atau client 1 ,USB to TTL , software pengubah teks menjadi sinyal cahaya yaitu Hyper terminal Communication, serta sumber radiasi berupa LED. Pada blok bagian Receiver terdiri atas photodetector, software pengubah cahaya menjadi sinyal listrik berupa teks, USB to TTL dan penerima informasi atau Client 2. Hasil dari proyek akhir ini adalah dapat mengirim data berupa teks melalui komputer 1 ke komputer 2 menggunakan sistem VLC. Parameter uji keberhasilan adalah jarak pengiriman dapat mencapai 2 meter, serta dapat mengirim dan menerima semua karakter mulai dari huruf, angka, dan simbol dengan sudut maksimal pengiriman yang terbentuk yaitu dari $0^{\circ}, 5^{\circ}, 10^{\circ}, 15^{\circ}$, sampai $20^{\circ}$.
\end{abstract}

Keywords - LED, VLC untuk pengiriman teks, Hyper terminal Communication, blok Transmiter dan Receiver VLC.

\section{PENDAHULUAN}

Perkembangan teknologi menciptakan banyak inovasi, salah satunya adalah lampu rumah berbasis LED yang nantinya tidak hanya digunakan sebagai penerangan saja tetapi juga untuk media komunikasi. cahaya LED digunakan pemanfaatan Visible Light Communication.

VLC atau komunikasi cahaya tampak adalah teknologi terobosan yang saat ini sedang dikembangkan dimana informasi dikirim melalui media cahaya tampak.

VLC merupakan media komunikasi data menggunakan cahaya tampak antara 400 $\mathrm{THz}(375 \mathrm{~nm})$ sampai $800 \mathrm{THz} \quad(780 \mathrm{~nm})$. Sistem ini memiliki transmiter yang berfungsi mengirim sumber informasi yang akan dikirim, media perantara berupa cahaya, serta receiver untuk menerima data yang dikirim. Pada blok trensmiter dapat ditambah blok reapeter untuk menguatkan sumber informasi sehingga jarak tempuh informasi bisa lebih jauh. Sumber radiasi atau sumber cahaya yang digunakan dapat berupa LED dan Laser. VLC sendiri merupakan teknologi telekomunikasi berbasis cahaya yang nantinya akan menggantikan komunikasi berbasis kabel tembaga dan pengganti teknologi wireless.

Sampai saat ini pengembangan dan inovasi teknologi VLC untuk pengiriman teks hanya dapat dilakukan pengiriman teks secara satu arah pada jarak $20 \mathrm{~cm}$, dan untuk VLC pengiriman teks secara Full duplex hanya dapat berkomunikasi pada jarak $5 \mathrm{~cm}^{[2]}$.

\section{DASAR TEORI}

\subsection{Visible Light Communication ${ }^{[2][3]}$}

$\begin{array}{ccr}\text { Visible } & \text { Light } & \begin{array}{r}\text { Communication } \\ \text { (VLC) adalah }\end{array} \text { media } \\ \text { komunikasi data }\end{array}$
menggunakan cahaya tampak antara $400 \mathrm{THz}$ $(375 \mathrm{~nm})$ sampai $800 \mathrm{THz}(780 \mathrm{~nm})$. Teknologi komunikasi ini memanfaatkan sumber cahaya yaitu LED sebagai transmitter, cahaya sebagai media transmisi, dan photodetector sebagai receiver.

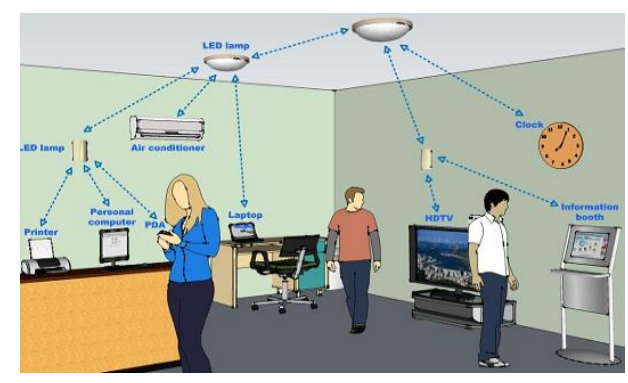

Gambar 2.1 : Visible Light Communication

VLC dapat digunakan sebagai media komunikasi untuk komputasi di mana pun, karena perangkat penghasil cahaya (seperti lampu indoor / outdoor, TV, rambu lalu lintas, iklan komersial, lampu depan dan belakang mobil) digunakan di mana-mana 


\subsection{USB to TTL Converter dan Hyper Terminal Communication}

Pada system Visible Light Communication (VLC) untuk pengiriman teks, USB to TTL Coverter diperlukan untuk merubah sinyal input teks ke sinyal elektrik baik untuk dikirim melalui kaki Tx USB to TTl Converter atau untuk menerima keluaran teks dengan kaki Rx pada USB ro TTl Converter.

Sedangkan Hyper Terminal Communication merupakan suatu software yang dapat digunakan untuk saling berkomunikasi antar 2 user melalui laptop

\subsubsection{USB to TTL Converter}

Perangkat usb to ttl merupakan salah satu jenis kabel converter yang mengkonversi data dari usb ke serial. Kabel usb to ttl ini memungkinkan pengguna untuk membuat perangkat elektronika mikrokontroller nya dapat berkomunikas. Usb to ttl memiliki keluaran beupa $V c c$, transmitter, receiver, dan ground.

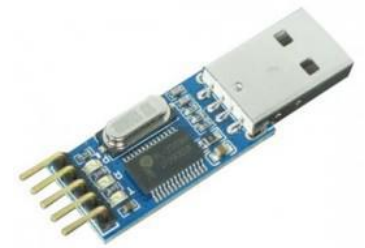

Gambar 2.2 : USB to TTL Converter

\subsubsection{Hyper Terminal Communication}

Suatu Software sebagai pengirim dan penerima teks pada layar computer, dimana antar 2 komputer saling berkomunikasi melalui terminal port yang tersedia pada computer, dimana kecepatan transmit data dapat ditur oleh masingmasing user tergantung dari jenis USB To converter TTL yang digunakan masing-masing laptop.

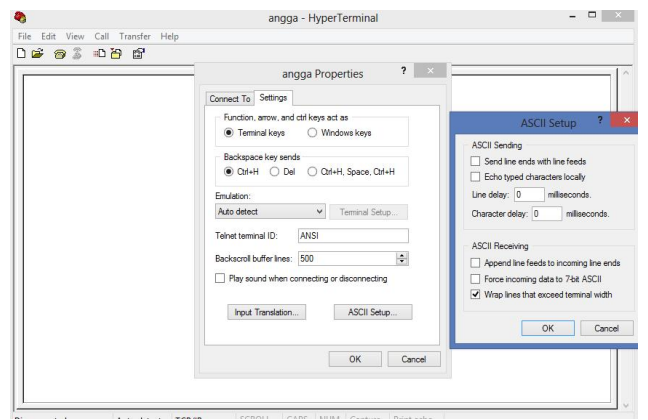

Gambar 2.3 : Hyper Terminal Communication

\subsection{Komunikasi Serial ${ }^{[4]}$}

Ada 2 macam cara komunikasi data serial yaitu Sinkron dan Asinkron. Pada komunikasi data serial sinkron, clock dikirimkan bersama sama dengan data serial, tetapi cloc tersebut dibangkitkan sendiri - sendiri baik pada sisi pengirim maupun penerima Sedangkan pada komunikasi serial asinkron tidak diperlukan clock karena data dikirimkan dengan kecepatan tertentu yang sama baik pada pengirim / penerima. Pada IBM PC kompatibel port serialnya termasuk jenis asinkron. Komunikasi data serial ini dikerjakan oleh UART (Universal Asynchronous Receiver Transmitter). IC UART dibuat khusus untuk mengubah data parallel menjadi data serial dan menerima data serial yang kemudian dirubah lagi menjadi data parallel. receiver harus sinkron. Untuk itu diperlukan". Ketika saluran transmisi dalam keadaan idle, output UART adalah dalam keadaan logika "1". Sebagai contoh misalnya akan dikirimkan data huruf "A" dalam format ASCII (atau sama dengan 41 heksa atau 01000001

\section{O VOLT \\ Gambar 2.4 Pengiriman huruf A tanpa bit paritas}

\section{BAB III \\ IMPLEMENTASI VISIBLE LIGHT COMMUNICATION (VLC) UNTUK PENGIRIMAN TEKS}

Pada bab ini membahas tentang perancangan hardware dari VLC berbasis pengiriman teks. Secara garis besar, hardware dari sistem ini terbagi menjadi 2 blok utama, yaitu blok transmiter dan blok receiver dari sistem $V L C$ berbasis pengiriman teks.

\subsection{Perancangan pada Hardware}

Langkah - langkah yang harus dilakukan untuk membuat $V L C$ berbasis pengiriman teks adalah sebagai berikut :

a. Menentukan rangkaian $V L C$ berbasis pengiriman teks.

b. Menentukan blok dan spesifikasi sistem yang dibuat.

c. Menentukan komponen yang akan digunakan.

d. Melakukan simulasi untuk setiap blok yang dapat dibuat untuk disimulasikan..

e. Blok-blok yang telah disimulasikan tersebut dibuat dan diuji.

f. Setelah Semua blok dibuat dan tidak muncul masalah, maka seluruh blok diimplementasikan hingga terbuat sebuah sistem $V L C$ berbasis pengiriman teks. 


\subsection{Cara Kerja Sistem}

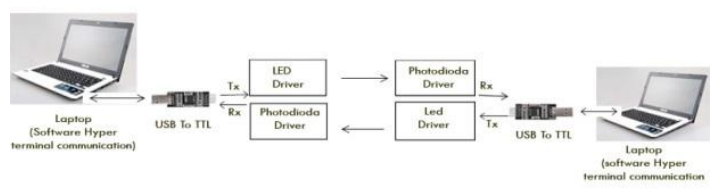

Gambar 3.1 Block Transmiter dan Block Receiver

Input Teks berasal dari laptop dengan software hyper terminal communication, kemudian akan masuk perangkat USB to TTL Converter yang akan dikirim dengan kaki Tx. Dari kaki Tx akan masuk ke rangkaian led pengirim/led driver kemudian sinyal informasi elektrik akan dirubah menjadi sinyal informasi cahaya yang akan dikirim ke block Receiver.

Pada bock Receiver sinyal cahaya pembawa informasi akan masuk bagian photodiode penerima/photodiode driver dan akan dirubah dari sinyal cahaya menjadi sinyal elektrik pembawa informasi. Kemudian sinyal informasi elektrik masuk ke kaki Rx pada USB to TTL Converter dan akan ditampilkan di laptop dengan software Hyper Terminal Communication. Untuk kaki ground USB to TTL converter Block transmitter dengan block receiver harus terintegrasi

\section{BAB IV : \\ PENGUJIAN DAN ANALISIS HASIL IMPLEMENTASI}

Bab ini berisi bahasan dari hasil implementasi dari seluruh blok diagram yang telah digambarkan pada bab sebelumnya.

\subsection{Pengujian dan Analisis Setiap Blok}

Pengujian dilakukan disetiap blok menggunakan osiloskop dengan jarak $50 \mathrm{~cm}$ antara Transmitter dan Receiver. Pada pengujian system per blok, karakter yang dikirim dari Transmitter dan Receiver adalah "huruf n" Pengujian dilakukan dalam beberapa tahap, antara lain :

a. Pengukuran sinyal Input pada kaki Tx

Pengujian dan pengukuran dilakukan pada kaki Tx(USB to TTL converter) sebelum masuk ke LED Driver dan mengalami penguatan sinyal. Kaki Tx(USB to TTL converter) dihubungkan ke kabel merah osiloskop dan kaki Ground(USB to TTL converter) dihubungkan ke kabel hitam osiloskop. Karakter yang dikirim adalah "huruf n"

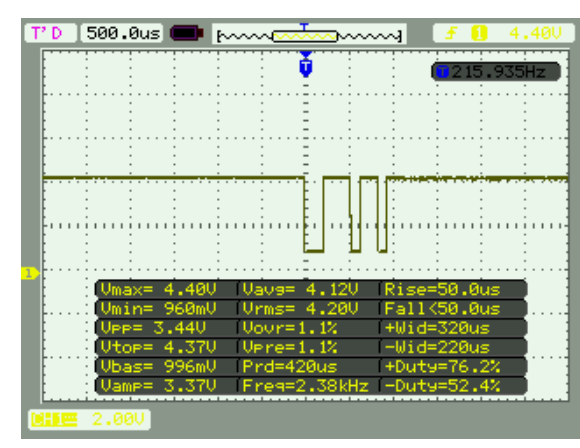

Gambar 4.1 : Sinyal input Sebelum dikuatkan

b. Pengukuran sinyal Input setelah dikuatkan Pengujian dan pengukuran dilakukan pada blok LED Driver dan mengalami penguatan sinyal. Katoda LED dihubungkan ke kabel merah osiloskop dan kaki Ground(USB to TTL converter) dihubungkan ke kabel hitam osiloskop. Karakter yang dikuatkan adalah "huruf n"

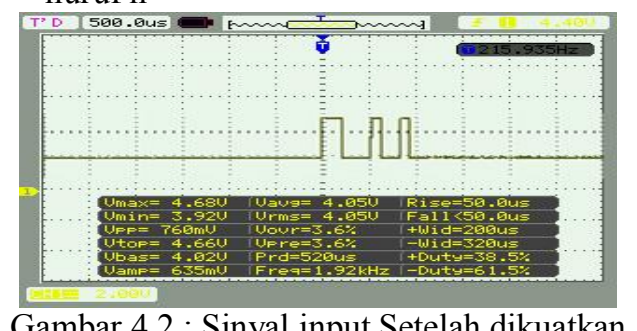

c. Pengukuran sinyal Output pada Photodioda Driver

Pengujian dan pengukuran dilakukan pada blok Photodioda Driver dimana sinyal yang diterima belum mengalami penguatan sinyal. Kaki negative kapasitor dihubungkan ke kabel merah osiloskop dan kaki Ground(USB to TTL converter) dihubungkan ke kabel hitam osiloskop. Karakter yang diterima adalah "huruf n"

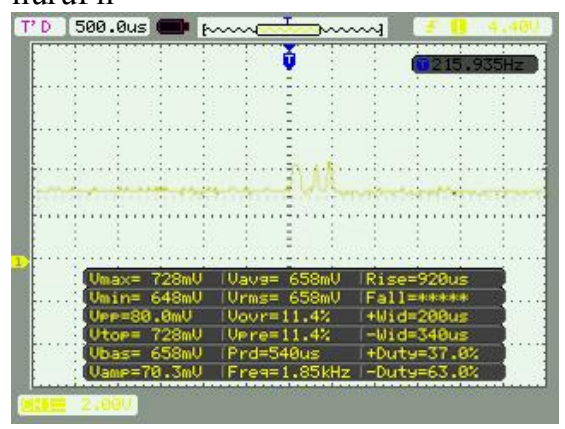

Gambar 4.3 : Sinyal output sebelum dikuatkan

d. Pengukuran Sinyal Output setelah dikuatkan Pengujian dan pengukuran dilakukan pada kaki $\operatorname{Rx}($ USB to TTL converter) setelah masuk ke Photodioda Driver dan mengalami penguatan sinyal. Kaki $\mathrm{Rx}$ (USB to TTL converter) dihubungkan ke kabel merah 
osiloskop dan kaki Ground (USB to TTL converter) dihubungkan ke kabel hitam osiloskop. Karakter yang diterima dan dikuatkan adalah "huruf n"

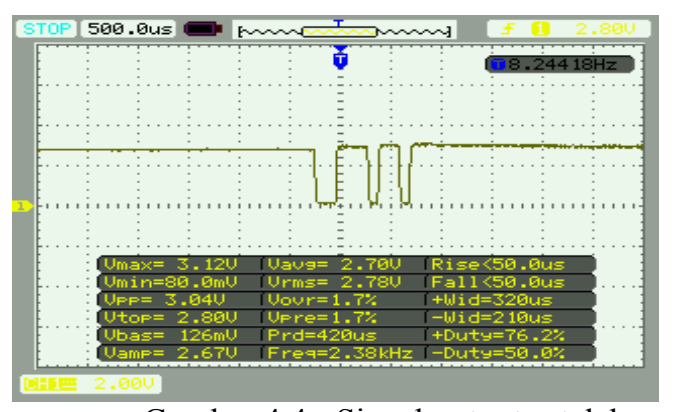

Gambar 4.4 : Sinyal output setelah dikuatkan

\subsection{Pengukuran blok sistem keseluruhan}

Pengukuran dilakukan pada sudut $0^{\circ}, 25^{\circ}$, $45^{\circ}, 70^{\circ}, 90^{\circ}$ dengan jarak sampai 3 meter Dengan 5 kali pengukuran diambil nilai rata-rata jarak yang maksimal untuk menghasilkan kualitas data(teks) yang baik dan hanya melakukan percobaan sampai jarak 3 meter untuk mengetahui nilai daya. Cara perhitungan Daya (dB) adalah $10 \log \left(\mathbf{V}^{*} \mathbf{I}\right)$, dimana $\boldsymbol{V}$ adalah selisih antara tegangan stand by (penerima aktif dan siap menerima informasi) dengan tegangan ketika penerima telah menerima informasi. Dan $I$ adalah selisih antara Arus Stand By (penerima aktif dan siap menerima informasi) dengan arus ketika penerima telah menerima informasi.

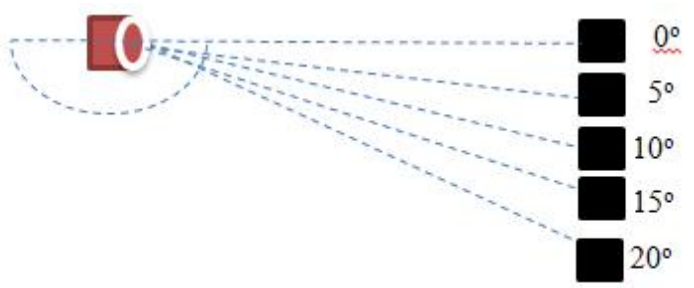

Gambar 4.5 Simulasi pengukuran sudut

\subsubsection{Kondisi Lingkungan Gelap}

Pengukuran dan pengujian dilakukan pada kondisi gelap(sedikit cahaya matahari dan lampu) dengan tegangan 9v pada Transmiter dan receiver serta jarak dan sudut yang telah ditentukan.

Tegangan stand by $=2,910 \mathrm{~V}$

Arus stand by $=0,13 \mathrm{~mA}$

Tabel 4.1 Data pengukuran nilai tegangan kondisi gelap sudut $0^{\circ}$

\begin{tabular}{|c|c|c|c|}
\hline No & Jarak & $\begin{array}{c}\text { Tegangan } \\
(\mathbf{V})\end{array}$ & $\begin{array}{c}\text { Daya } \\
(\mathbf{d B m})\end{array}$ \\
\hline $\mathbf{1}$ & $0.5 \mathrm{~m}$ & $0,0355 \mathrm{~V}$ & $\mathbf{6 , 6 4 1}$ \\
\hline $\mathbf{2}$ & $1 \mathrm{~m}$ & $0,0303 \mathrm{~V}$ & $\mathbf{5 , 9 5}$ \\
\hline $\mathbf{3}$ & $1,5 \mathrm{~m}$ & $0,026 \mathrm{~V}$ & $\mathbf{5 , 2 8 9}$ \\
\hline $\mathbf{4}$ & $2 \mathrm{~m}$ & $0,021 \mathrm{~V}$ & $\mathbf{4 , 3 6 1}$ \\
\hline $\mathbf{5}$ & $3 \mathrm{~m}$ & $0,0159 \mathrm{~V}$ & $\mathbf{3 , 1 5}$ \\
\hline
\end{tabular}

Tabel 4.2 Data pengukuran nilai tegangan kondisi gelap sudut $5^{\circ}$

\begin{tabular}{|c|c|c|c|}
\hline No & Jarak & $\begin{array}{c}\text { Tegangan } \\
(\mathbf{V})\end{array}$ & $\begin{array}{c}\text { Daya } \\
\text { (dBm) }\end{array}$ \\
\hline $\mathbf{1}$ & $0.5 \mathrm{~m}$ & $0,028 \mathrm{~V}$ & $\mathbf{5 , 2 6 3}$ \\
\hline $\mathbf{2}$ & $1 \mathrm{~m}$ & $0,015 \mathrm{~V}$ & $\mathbf{2 , 9 0 0}$ \\
\hline $\mathbf{3}$ & $1,5 \mathrm{~m}$ & $0,006 \mathrm{~V}$ & $\mathbf{- 1 , 0 7 9}$ \\
\hline $\mathbf{4}$ & $2 \mathrm{~m}$ & $0,003 \mathrm{~V}$ & $\mathbf{- 4 , 0 8 9}$ \\
\hline $\mathbf{5}$ & $3 \mathrm{~m}$ & - & - \\
\hline
\end{tabular}

Tabel 4.3 Data pengukuran nilai tegangan kondisi gelap sudut $10^{\circ}$

\begin{tabular}{|c|c|c|c|}
\hline No & Jarak & $\begin{array}{c}\text { Tegangan } \\
(\mathbf{V})\end{array}$ & $\begin{array}{c}\text { Daya } \\
(\mathbf{d B m})\end{array}$ \\
\hline $\mathbf{1}$ & $0.5 \mathrm{~m}$ & $0,011 \mathrm{~V}$ & $\mathbf{1 , 5 5 3}$ \\
\hline $\mathbf{2}$ & $1 \mathrm{~m}$ & $0,004 \mathrm{~V}$ & $\mathbf{- 2 , 8 3 9 9}$ \\
\hline $\mathbf{3}$ & $1,5 \mathrm{~m}$ & $0,002 \mathrm{~V}$ & $\mathbf{- 5 , 8 5 0}$ \\
\hline $\mathbf{4}$ & $2 \mathrm{~m}$ & - & - \\
\hline $\mathbf{5}$ & $3 \mathrm{~m}$ & - & - \\
\hline
\end{tabular}

Tabel 4.4 Data pengukuran nilai tegangan kondisi gelap sudut $15^{\circ}$

\begin{tabular}{|c|c|c|c|}
\hline No & Jarak & $\begin{array}{c}\text { Tegangan } \\
(\mathbf{V})\end{array}$ & $\begin{array}{c}\text { Daya } \\
(\mathbf{d B m})\end{array}$ \\
\hline $\mathbf{1}$ & $0.5 \mathrm{~m}$ & $0,0065 \mathrm{~V}$ & $\mathbf{- 0 , 7 3 1}$ \\
\hline $\mathbf{2}$ & $1 \mathrm{~m}$ & $0,0021 \mathrm{~V}$ & $\mathbf{- 5 , 6 3 8}$ \\
\hline $\mathbf{3}$ & $1,5 \mathrm{~m}$ & - & - \\
\hline $\mathbf{4}$ & $2 \mathrm{~m}$ & - & - \\
\hline $\mathbf{5}$ & $3 \mathrm{~m}$ & - & - \\
\hline
\end{tabular}

Dalam simulasi penelitian ini, dilakukan pengukuran sesuai parameter yang ditentukan. Pengukuran alat ini, di lakukan percobaan 5 kali dengan kondisi jarak dan sudut yang berbeda . Pada pengukuran kondisi waktu gelap, semakin jauh jarak semakin kecil nilai daya. Percobaan dilakukan sesuai jarak dan sudut yang berbeda, sehingga nilai tegangan dan daya pada sudut $0^{\circ}, 5^{\circ}, 10^{\circ}, 15^{\circ}$, dan $20^{\circ}$.

Hasil percobaan dari alat yang disimulasikan ini, semakin jauh jarak yang ditempuh, serta semakin besar sudut yang terjadi antara Transmitter dan Receiver maka semakin kecil daya yang dihasilkan dan dapat menyebabkan sinyal informasi gagal dikirim.

Kesimpulan pengujian dari faktor jarak dan sudut saat kondisi gelap

1. Data Teks dapat diterima secara sempurna pada sudut $0^{\circ}$ pada jarak maksimal pengiriman sejauh 3 meter

2. Data teks dapat diterima namun teks yang diterima tidak sempurna pada sudut $5^{\circ}, 10$ ${ }^{\circ}, 15^{\circ}$, dan $20^{\circ}$ pada jarak tertentu

3. Data Teks tidak dapat diterima pada sudut $5^{\circ}, 10^{\circ}, 15^{\circ}$, dan $20^{\circ}$ pada jarak tertentu

\subsubsection{Kondisi Lingkungan Terang}


Pengukuran dan pengujian dilakukan pada kondisi terang(adanya cahaya matahari dan lampu) dengan tegangan 9v pada Transmiter dan receiver serta jarak dan sudut yang telah ditentukan Tegangan stand by $=2,920 \mathrm{~V}$ Arus stand by $=0,13 \mathrm{~mA}$

Tabel 4.1 Data pengukuran nilai tegangan kondisi terang sudut $0^{\circ}$

\begin{tabular}{|c|c|c|c|}
\hline No & Jarak & $\begin{array}{c}\text { Tegangan } \\
(\mathbf{V})\end{array}$ & $\begin{array}{c}\text { Daya } \\
(\mathbf{d B m})\end{array}$ \\
\hline $\mathbf{1}$ & $0,5 \mathrm{~m}$ & $0,021 \mathrm{~V}$ & $\mathbf{4 , 3 6 1}$ \\
\hline $\mathbf{2}$ & $1 \mathrm{~m}$ & $0,0205 \mathrm{~V}$ & $\mathbf{4 , 2 5 6}$ \\
\hline $\mathbf{3}$ & $1,5 \mathrm{~m}$ & $0,020 \mathrm{~V}$ & $\mathbf{4 , 1 4 9}$ \\
\hline $\mathbf{4}$ & $2 \mathrm{~m}$ & $0,017 \mathrm{~V}$ & $\mathbf{3 , 4 4 3}$ \\
\hline $\mathbf{5}$ & $3 \mathrm{~m}$ & $0,010 \mathrm{~V}$ & $\mathbf{1 , 1 3 9}$ \\
\hline
\end{tabular}

Tabel 4.2 Data pengukuran nilai tegangan kondisi terang sudut $5^{\circ}$

\begin{tabular}{|c|c|c|c|}
\hline No & Jarak & $\begin{array}{c}\text { Tegangan } \\
(\mathbf{V})\end{array}$ & $\begin{array}{c}\text { Daya } \\
(\mathbf{d B m})\end{array}$ \\
\hline $\mathbf{1}$ & $0,5 \mathrm{~m}$ & $0,022 \mathrm{~V}$ & $\mathbf{4 , 5 6 3}$ \\
\hline $\mathbf{2}$ & $1 \mathrm{~m}$ & $0,012 \mathrm{~V}$ & $\mathbf{1 , 9 3 1}$ \\
\hline $\mathbf{3}$ & $1,5 \mathrm{~m}$ & $0,003 \mathrm{~V}$ & $\mathbf{- 4 , 0 8 9}$ \\
\hline $\mathbf{4}$ & $2 \mathrm{~m}$ & - & - \\
\hline $\mathbf{5}$ & $3 \mathrm{~m}$ & - & - \\
\hline
\end{tabular}

Tabel 4.3 Data pengukuran nilai tegangan kondisi terang sudut $10^{\circ}$

\begin{tabular}{|c|c|c|c|}
\hline No & Jarak & $\begin{array}{c}\text { Tegangan } \\
(\mathbf{V})\end{array}$ & $\begin{array}{c}\text { Daya } \\
(\mathbf{d B m})\end{array}$ \\
\hline $\mathbf{1}$ & $0,5 \mathrm{~m}$ & $0,010 \mathrm{~V}$ & $\mathbf{1 , 1 3 9}$ \\
\hline $\mathbf{2}$ & $1 \mathrm{~m}$ & $0,002 \mathrm{~V}$ & $\mathbf{- 5 , 8 5 0}$ \\
\hline $\mathbf{3}$ & $1,5 \mathrm{~m}$ & - & - \\
\hline $\mathbf{4}$ & $2 \mathrm{~m}$ & - & - \\
\hline $\mathbf{5}$ & $3 \mathrm{~m}$ & - & - \\
\hline
\end{tabular}

Tabel 4.4 Data pengukuran nilai tegangan kondisi terang sudut $15^{\circ}$

\begin{tabular}{|c|c|c|c|}
\hline No & Jarak & $\begin{array}{c}\text { Tegangan } \\
(\mathbf{V})\end{array}$ & $\begin{array}{c}\text { Daya } \\
(\mathbf{d B m})\end{array}$ \\
\hline $\mathbf{1}$ & $0,5 \mathrm{~m}$ & $0,005 \mathrm{~V}$ & $\mathbf{- 1 , 8 7 0}$ \\
\hline $\mathbf{2}$ & $1 \mathrm{~m}$ & - & - \\
\hline $\mathbf{3}$ & $1,5 \mathrm{~m}$ & - & - \\
\hline $\mathbf{4}$ & $2 \mathrm{~m}$ & - & - \\
\hline $\mathbf{5}$ & $3 \mathrm{~m}$ & - & - \\
\hline
\end{tabular}

Dalam penelitian ini, dilakukan pengukuran sesuai parameter yang ditentukan. Pengukuran alat ini, di lakukan percobaan 5 kali dengan kondisi jarak dan sudut yang berbeda . Pada pengukuran kondisi waktu terang, semakin jauh jarak semakin kecil nilai daya. Percobaan dilakukan sesuai jarak dan sudut yang berbeda, sehingga didapat nilai tegangan dan daya pada sudut $0^{\circ}, 5^{\circ}$, $10^{\circ}, 15^{\circ}$, dan $20^{\circ}$.

Hasil percobaan adalah semakin besar sudut yang terjadi antara Transmitter dan Receiver maka semakin kecil daya yang dihasilkan dan dapat menyebabkan sinyal informasi gagal dikirim.

Kesimpulan pengujian dari faktor jarak dan sudut saat kondisi terang

1. Data Teks dapat diterima secara sempurna pada sudut $0^{\circ}$ pada jarak maksimal pengiriman sejauh 3 meter

2. Data teks dapat diterima namun teks yang diterima tidak sempurna pada sudut $5^{\circ}, 10$ ${ }^{\circ}, 15^{\circ}$, dan $20^{\circ}$ pada jarak tertentu

3. Data Teks tidak dapat diterima pada sudut $5^{\circ}, 10^{\circ}, 15^{\circ}$, dan $20^{\circ}$ pada jarak tertentu.

\subsection{Kesimpulan}

\section{BAB V}

\section{KESIMPULAN DAN SARAN}

Dari implementasi dan analisis sistem VLC untuk pengiriman teks yang telah dilakukan, maka diambil beberapa kesimpulan, di antaranya:

a. Perancangan dan implementasi Visible Light Communication (VLC) untuk pengiriman teks dapat dibuat dan dijalankan

b. Pada VLC untuk pengiriman teks, karakter huruf dan angka dapat dikirim dari transmitter ke receiver menggunakan cahaya LED

c. Karakter kata yang dikirim dari Transmiter ke Receiver dapat rusak atau terbaca secara tak sempurna

d. Kondisi lingkungan gelap dan terang mempengaruhi jarak pengiriman teks dari Transmiter ke Receiver.

e. Sudut yang terbentuk dari Transmiter ke Receiver mempengaruhi jarak pengiriman teks.

\section{DAFTAR PUSTAKA}

[1] Digiware. Pengetahuan Komponen Pasif Elektronika 1. Jakarta : Erlangga.

[2]_Durgesh Gujjari .Visible Light Communication. Dalhousie University. Halifax, Nova. Scotia August 2012

[3] Farida Purnama Sari. 2012. Implementation and Analysis of LED-Based FM Radio Repeater". Telkom University

[4] Iddhien. 2006. Pemrograman Port Serial. Bandung

[5] I Gusti Ngurah Suryantara. 2011. PENCAHAYAAN. Jakarta

[6] Kaiser, Gerd. 1991.Optical Fiber Communication. Mc. Graw Hill

[7] Paul E. Green. "Fiber To The Home The New Empowerment". John Willey, England 2006.

[8] William Stallings. Komunikasi Data dan Komputer Edisi ke 7. Teknik Komunikasi Data Digital 